\title{
Saint-Aubin de Poitiers, La Coupe de cheveux
}

\section{Michel Arrous}

\section{(2) OpenEdition}

\section{Journals}

\section{Édition électronique}

URL : http://journals.openedition.org/studifrancesi/6676

DOI : 10.4000/studifrancesi.6676

ISSN : 2427-5856

\section{Éditeur}

Rosenberg \& Sellier

\section{Édition imprimée}

Date de publication : 1 septembre 2010

Pagination : 381

ISSN : 0039-2944

\section{Référence électronique}

Michel Arrous, «Saint-Aubin de Poitiers, La Coupe de cheveux », Studi Francesi [En ligne], 161 (LIV | II) |

2010, mis en ligne le 30 novembre 2015, consulté le 08 janvier 2021. URL : http://

journals.openedition.org/studifrancesi/6676 ; DOI : https://doi.org/10.4000/studifrancesi.6676

Ce document a été généré automatiquement le 8 janvier 2021.

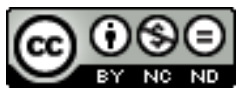

Studi Francesi è distribuita con Licenza Creative Commons Attribuzione - Non commerciale - Non opere derivate 4.0 Internazionale. 


\title{
Saint-Aubin de Poitiers, La Coupe de cheveux
}

\author{
Michel Arrous
}

\section{RÉFÉRENCE}

SAINT AUBIN DE POITIERS, La Coupe de cheveux, vaudeville en un acte représenté pour la première et unique fois le 17 mai 1828 sur la scène du Théâtre du Vaudeville. Note sur un fragment détaché de Un Roman pour les cuisinières d'Émile Cabanon, Paris, La Rose de Java, 2009, pp. 138.

D'après Un Roman pour les cuisinières, les Parisiens auraient gardé en 1834 la mémoire de l'unique représentation de La Coupe de cheveux, en 1828, sans doute pour son caractère «ébouriffant» et «d'un grotesque pyramidal». On n'en parla que deux jours, et de l'auteur pas davantage, si ce n'est qu'au dire de Cabanon il était «grand officier du Château et parfait gentilhomme». Jean-Jacques Tomasso a retrouvé le texte inédit de ce «vaudeville excessif» - selon l'expression de Cabanon - dans les cartons de la Censure qui eut à juger de sa parfaite innocuité, à un couplet près. De ce scandale d'un soir témoigne une poignée d'articles dans les feuilles littéraires et les "petits journaux», particulièrement Le Figaro qui, à deux reprises, exerça sa verve contre l'auteur - un grand seigneur perruquier? - et le directeur du théâtre dont on se demanda pourquoi ils avaient osé pareil ouvrage (Arnal, dans le rôle du valet Jasmin, fit son possible pour entretenir l'hilarité générale en se moquant spirituellement de ce qu'il avait à dire). Les grands quotidiens ignorèrent l'événement; seul Le Globe, en l'occurrence Dittmer et Cavé, soutint contre la plupart des feuilletons l'hypothèse de la mystification. Dans ses efforts pour percer le mystère Saint-Aubin, J.-J. Tomasso a fait preuve d'une louable perspicacité: débusquer sous ce pseudonyme omnibus le possible auteur de La Coupe de cheveux se présentait comme une tâche fort ingrate tant furent nombreux sur les scènes de la Restauration les Saint-Aubin de Poitiers ou d'ailleurs. Entre autres pistes, celle de Balzac (alias Horace de Saint-Aubin) associé à Le Poitevin est minutieusement examinée; en vain, et l'auteur de ce pastiche volontaire ou non reste dans l'anonymat le 
plus complet. Quand on sait que des vingt et une pièces données au Vaudeville cette année-là, quatre seulement, dont cette Coupe de cheveux, ne furent pas éditées, on se dit que J.-J. Tomasso a eu bien raison de saisir l'occasion aux cheveux en s'intéressant à cette œuvrette ambiguë, «la chose la plus incroyable qui ait jamais désopilé la rate du public» (Le Figaro), dont il restera, grâce à ses bons soins et à une présentation impeccable, plus que des papillotes! 